\title{
РОССИЯ - ЕС: ПОЛИТИКА И ТОРГОВЛЯ
}

Аннотация. Сегодня отношения России с ЕС опустились до крайне низкого уровня. Их определяют действующие пакеты политических и экономических санкций, введённых Евросоюзом против России в период с марта 2014 г. до настоящего времени. Они предусматривают запрет на въезд в ЕС ряда высокопоставленных представителей российского чиновни-чества и представителей бизнеса, высылку российских дипломатов и ряд мер по ограничению торгово-экономических связей. Негативным политическим итогом санкций стал рост антироссийских настроений в Европе и частичная изолящия России. Будущее России настоятельно требует выхода из сложившегося тупика в отношениях с Западом.

Ключевые слова: Россия, ЕС, США, торговля, инвестиции.

Конфликт между Россией и ЕС основан на двух противоречащих друг другу требованиях. Запад считает непременным условием восстановление нормальных отношений с ЕС, США и такими странами как Украина и Грузия признание Россией норм международного права, которые с их точки зрения, далеко не всегда ими соблюдаются. Со своей стороны, РФ настаивает, как на своём праве защищать русских и русскоговорящих за пределами своих государственных границ, так и на признание России одним из глобальных центров ${ }^{1}$. Вероятно, на Западе могут формально признать многополярность мира, а Россию одним из его центров, но действия российского государства в объявленной им «зоне влияния» не всегда устраивают ни ближайших соседей, ни большинство стран мира, не признающих Абхазию, Южную Осетию и «возвращение Крыма в родную гавань». Ссылки на то, что свою зону влияния имеют такие страны как США, Великобритания или Франция не всегда соответствуют историческим реалиям. Соединённые Штаты привлекают союзников гарантиями их безопасности и экономическими выгодами сотрудничества. Париж и Лондон смогли сохранить определённое влияние в своих бывших колониальных империях тщательно выверенной политикой и достаточно ос-торожным отношением к внутренним проблемам новых государств. Опыт развала СССР и со-циалистической системы, к сожалению, не стал для нас уроком построения союзных отноше-ний. Об этом говорит не слишком удачный опыт СНГ, не говоря уже о событиях вокруг Ук-раины, ставших главным фактором, породившим политику санкций.

Стремление Кремля сохранить Киев в орбите своих политических интересов очевидно, и до сих пор находится в рамках максимум включения Украины в орбиту российских интере-

\footnotetext{
() Носов Михаил Григорьевич - член-корреспондент РАН, главный научный сотрудник Отдела европейской безопасности, член дирекции Института Европы РАН. Aдрес: 125009, Россия, Москва, ул. Моховая, д.11, стр. 3. E-mail: mikhailnosov@mail.ru
}

DOI: http://dx.doi.org/10.15211/vestnikieran420196167

1 По мнению близко знакомого с российской политикой научного директора Германо-Российского форума Александра Рара, «первое, что хочет Россия, - уважение, респект, чтобы её перестали рассматривать как страну, которая проиграла «холодную войну». Если бы политики на Западе лучше бы понимали менталитет сегодняшней отечественной политической элиты, они давно бы нашли способ убедить её в ошибочности подобных подозрений. 
сов, минимум - не допущение её вступления в НАТО. Столь же очевидно, что спустя почти пять лет после Майдана эти расчёты не оправдались и лишь породили глубокий и болезненный раскол между двумя братскими народами и растущее недоверие к нашей политике на За-паде. Однако «украинский фактор» был не единственным в возникновении настороженности к российской политике. К сожалению, наше государство за эти годы много раз давало достаточно весомые поводы для подобного отношения к его действиям. Вне зависимости от определения подлинных виновников того или иного инцидента, информационно-пропагандист-ский шум вокруг них не прибавил авторитета российской внешней политике.

Сегодня страны ЕС далеко не единодушны по вопросу о санкциях в отношении РФ, тем более что они оказывают негативное воздействие не только на Россию, но и на экономику многих европейских стран. По отношению к санкциям страны ЕС можно разделить на несколько групп. Их инициатором выступили Германия, Великобритания, Швеция и Дания, к которым присоединились Польша, страны Балтии и Финляндия. Менее уверены в их эффективности Франция, Испания, Португалия и Нидерланды. Большинство других стран, среди которых поддерживающие тесные экономические связи с Россией Италия, Венгрия, Австрия, Греция и Кипр, настроены негативно к дальнейшей пролонгации ограничительных мер. Их поддерживает большинство стран восточной Европы, имеющие традиционные связи с Россией. Однако эти разногласия до сих пор не привели к голосованию в её пользу по вопросу о санкциях.

Не оправдались и надежды на то, что брекзит или движение за независимость Каталонии ослабят единство Европейского союза, что приведёт к прорыву санкционной блокады. Как любая огромная и сложная структура ЕС всегда будет переживать кризисы, но это болезни роста, а не деградация, как рассчитывают многие как в самом союзе, так и за его пределами. Проблемы эмиграции внесли серьёзные разногласия в руководство стран - членов ЕС, однако демократически основы организации находят сегодня и будут находить в будущем платформу для решения возникшей проблемы. В конечном итоге выгоды единства будут превалировать над центробежными силами. Сегодня западные санкции остаются реальностью, а возможность их снятия в обозримом будущем маловероятна. Тем не менее, обе стороны должны даже в условиях конфронтации искать пути для преодоления кризиса в двусторонних отношениях. И ЕС и Россия должны предложить контуры цивилизованных отношений, включая соблюдение согласованных правил и норм общения.

\section{Торговля: Россия - ЕС}

Несмотря на санкции, ЕС остаётся главным торговым партнёром России. В 2018 г. российский экспорт составил $2 \%$ от мирового, а импорт 1,3\%. По импорту Россия находится на 21-м месте в мире, по экспорту на 15-м (таблица 1).

В экспорте ЕС доля России в 2018 г. составила 4\%, а в импорте $8 \%$. В российском экспорте доля ЕС равна37,5\%, в импорте - 45,6\%. На Германию среди стран ЕС пришлось $16,6 \%$ российского экспорта и $28,6 \%$ импорта. На Нидерланды ${ }^{1}$ - соответственно $21,2 \%$ и $4,1 \%$.

В 2018 г. в импорте России из стран ЕС 22,9\% пришлось на продукцию общего машиностроения, $11,5 \%$ на автомобили, 8,6\% на лекарственные препараты, 7,4\% на электротехнические товары. В отечественном экспорте доля ценных металлов равна 2,3\%,

\footnotetext{
1 Это связано в первую очередь с «эффектом Роттердама», поскольку через этот порт проходит значительная часть импорта энергоносителей Евросоюза.
}

Научно-аналитический вестник ИЕ РАН, 2019, №4 
железа и стали $-3,2 \%$, машин и оборудования $-0,9 \%$.

Минеральное топливо было и остаётся экономической основой отношений между Россией и ЕС. Хотя стоимость российского импорта энергоносителей в денежном выражении со-кратилась на треть, это не отразилось на объёмах поставок, которые в целом за период между 2013 и 2018 гг. выросли и составили 60,9\% от объёма российского экспорта в ЕС в 2018 г. Россия остаётся крупнейшим поставщиком газа в ЕС. Её доля в поставках газа в ЕС в 2018 г. составила 47,1\%², в поставках нефти в ЕС - 26,9\% (таблица 2). Зависимость ЕС от импорта минерального топлива сохраняется на уровне свыше $50 \%{ }^{3}$.

Однако существует по крайней мере две угрозы стабильности поставок российского энергетического сырья в ЕС. Зависимость ЕС от импорта минерального топлива пока увеличивается - по нефти с 2010 по 2016 гг. с 84,5\% до 86,7\%, а по газу - с 62,5 до 70,4\%. Однако продолжает расти и доля возобновляемых источников в энергетическом балансе ЕС. С 1995 по 2016 гг. она выросла с 5,1 до 13,2\%, а к 2020 г. должна достичь 20\%. В выработке электроэнергии доля возобновляемых источников в ЕС в 2016 г. составила 30,2\%, в отоплении $24,3 \%{ }^{4}$. Использование этих источников продиктовано не только стремлением избавиться от энергетической зависимости от России и других стран, но и экологическими соображениями.

Вторая опасность для российских поставок минерального сырья в Европу связана с политикой президента США в отношении ЕС. Трамп выступает против строительства «Северного потока - 2», преследуя при этом четыре цели. Во-первых, заставить Германию увеличить свой взнос в НАТО; во-вторых, создать в Европе рынок для будущих поставок американского СПГ, доля которого в импорте ЕС энергетического сырья пока незначительна ; в-третьих, оказать политическое давление на Германию, и в-четвёртых, вбить клин в отношения между Берлином и Москвой.

В 2017 г. инвестиции в Россию сократились на 32\% по сравнению с предыдущим годом и составили 25 млрд долл. В основном они направлялись в добычу минерального сырья (30\%), в торговлю $(20 \%)$ и в финансовый сектор (11\%). Основными инвесторами в российскую экономику были Кипр (25\%), Люксембург (14\%), а также Сингапур, Гонконг и Китай (по 7\%). Почти половина инвестиций - 11 млрд долл. - на покупку 19,5\% акций компании Роснефть консорциумом из швейцарской компании «Гленкор» и Катарского инвестиционного банка. Ещё 20\% акций Роснефти были куплены за 1 млрд долл. Пекинской газовой компанией ${ }^{6}$ В 2017 г. на Россию пришлось 1,75\% входящих инвестиций, доля РФ в мировых накопленных инвестициях на конец 2017 г. была равна 0,14\%7. Российские капиталовложения в экономику других стран в 2017 г. по сравнению с 2016 г. выросли на 34\% и составили 36 млрд долл. (2,5\% от мировых инвестиций). В основном они были направлены

\footnotetext{
${ }^{1}$ UN Comtrade. URL: https://comtrade.un.org/ (дата обращения: 08.03.2019).

${ }^{2}$ Вторым по значению поставщиком газа в ЕС является Норвегия, на которую пришлось в 2017 г. 37,7\%, а в первой половине 2018 г. 38,8\%. EU imports of energy products. URL: https://ec.europa.eu/eurostat/statistics-explained/ index.php/EU_imports_of_energy_products_-_recent_developments (дата обращения: 08.03.2019).

${ }^{3}$ Energy balance guide. European Commission, 2018. P. 10. URL: https://ec.europa.eu/eurostat/documents/38154/ 4956 218/ENERGY-BALANCE-GUIDE-DRAFT-31JANUARY2019.pdf/cf121393-919f-4b84-9059-cdf0f69ес045 (дата обращения: 08.03.2019).

${ }^{4}$ EU energy in figures. 2018. P. 21, 27.

${ }^{5}$ В 2017 г. 13 стран ЕС импортировали СПГ, что составило 11\% от объёма потребляемого ими газа. U.S.Energy Information Administration October 25, 2018. Доля СПГ в импорте ЕС энергетического сырья составила в стоимостном выражении в 2017 г. 2,7\%, в первой половине 2018 г. 2,5\%. [Extra-EU_imports]. Подробнее эта проблема рассмотрена в статье: Журкин В., Носов М. Дональд Трамп и Европа. Современная Европа, №4, 2018. С. 17-33.

6 World Investment Report 2018 UNCTAD, Geneva, 2018 P. 59. URL: https://unctad.org/en/PublicationsLibrary/ wir2018_en.pdf (дата обращения: 08.03.2019).

${ }^{7}$ Для сравнения на США приходится 24,8\% накопленных ПИИ, на Китай 4,7\%, на EC 28,9\%. World Investment.
} Научно-аналитический вестник ИЕ РАН, 2019, №4 
на слияния и поглощения зарубеж-ных компаний. Накопленные прямые иностранные инвестиции в российскую экономику на конец 2017 г. увеличились до 446,6 млрд, а зарубежные ПИИ России - до 382,3 млрд долл. (таблица 3).

\section{Планы и реальность}

Когда руководство страны ставит задачу «прорыва» в экономике и укрепления великодержавного статуса, отношения с коллективным Западом и, прежде всего, с ЕС становятся важнейшим фактором, влияющим на достижение этих грандиозных по своим масштабам целей. На сегодняшний день Россия сохраняет ядерный паритет с Соединёнными Штатами, что гарантирует взаимоуничтожение, как друг друга, так и остального человечества в случае ядер-ной войны. По всем остальным военным и экономическим параметрам наша страна, к сожале-нию, утратила паритет с Западом. В 2017 г. военные расходы стран НАТО составили свыше 900 млрд долл., включая военный бюджет США в 610 млрд долл. и Канады в 20,6 млрд долл. Отечественные расходы на оборону в 2017 г. составили 66,3 млрд долл. ${ }^{1}$ Если для полномасштабной ракетно-ядерной войны эти затраты большой роли не играют, то для конвенциональной войны готовность войск и их оснащение зависят от потраченных средств.

Кризис в отношениях России с ЕС и другими странами Запада неизбежно скажется на планах развития нашей страны. Стать одним из важнейших центров мировой политики и экономики РФ должна не только за счёт ядерного потенциала или запасов нефти и газа, но и в силу своей политической и экономической привлекательности, которой сегодня нам катастрофически не хватает. В соответствии с указом президента «О национальных целях и стратегических задачах РФ на период до 2024 года» от 7 мая 2018 г. Россия должна войти в число пяти крупнейших экономик мира. Войти в пятёрку мы можем, если речь идёт о номинальном ВВП по ППС в долларах. В 2018 г. по этому показателю мы находились на шестом месте, ус-тупая Германии по этому показателю 199,5 млрд долл. Намного хуже ситуация с ВВП по ППС на душу населения, что в конечном итоге определяет уровень процветания государства. По прогнозу Международного валютного фонда (IMF) в 2018 г. душевой доход в России в теку-щих ценах составил 29 тыс. 32 долл. (65 место в мире), а к 2023 г. он вырастет до 34 тыс. 675 долл., что выведет нас на 56-е место в мире 2 . Россия имеет достаточно человеческих и сырьевых ресурсов для кардинального улучшения этого показателя, но сделать это возможно толь-ко при условии соблюдения двух основополагающих условий.

Первое, это соблюдение основных принципов демократии, поскольку в конечном итоге демократия и развитие находятся в прямой зависимости. Только гарантии верховенства закона, реальное разделение ветвей власти, независимая судебная система и сменяемость власти позволят достичь поставленных президентом экономических показателей. Достичь высоких показателей роста экономики в условиях авторитарного правления возможно, однако удерживать их значительно сложнее. Сегодня высочайшие темпы экономического развития демонстрирует Китай, но без серьёзных политических реформ в обозримом будущем он столкнётся со снижением темпов роста и неизбежным в этой ситуации политическим кризисом ${ }^{3}$.

\footnotetext{
${ }^{1}$ SIPRI Yearbook. 2018. P. 234. URL: https://www.sipri.org/yearbook/2018 (дата обращения: 08.03.2019).

2 IMF World Economic Outlook, 2018. URL: https://www.imf.org/external/pubs/ft/weo/2018/02/weodata/index.aspx (дата обращения: 08.03.2019).

3 Решение сессии ВСНП 13-го созыва в марте 2018 г. об отмене статьи Конституции КНР, ограничивающей полномочия председателя КНР двумя 5-летними сроками. Полномочия Си Цзиньпина по старой Конституции исте-
} Научно-аналитический вестник ИЕ РАН, 2019, №4 
Вторым условием, без соблюдения которого невозможно обеспечить экономический рост, является участие России в мировой экономике. РФ катастрофически отстаёт по расходам на НИОКР. В 2019 г. расходы США на эти цели оцениваются в 581 млрд долл., России - в 61,9 млрд долл., при этом очевидно, что они касаются как гражданских, так и военных разработок. Об опасности отставания в этой сфере в своём послании Федеральному собранию в марте 2018 г. говорил В.В. Путин: «Скорость технологических изменений нарастает стремительно, идёт резко вверх. Тот, кто использует эту технологическую волну, вырвется далеко вперёд. Тех, кто не сможет этого сделать, она - эта волна - просто захлестнёт, утопит» ${ }^{1}$. Оче-видно, что без сотрудничества с ЕС и с США технологическая волна действительно захлестнёт нашу экономику, а расчёт президента «на то, что наши ребята ещё чего-нибудь придума-ют», может не оправдаться.

Сегодня ещё не поздно восстановить отношения с Западом. В послании Федеральному собранию в феврале 2019 г. В.В. Путин выразил надежду, что «со стороны Евросоюза и ведущих стран Европы всё-таки будут предприняты реальные шаги по восстановлению нормальных политических и экономических отношений с Россией. Граждане этих стран заинтересованы в таком сотрудничестве с Россией» ${ }^{2}$. В сегодняшнем состоянии и экстраполируя наше развитие на будущее, РФ должна быть больше заинтересована в восстановлении нормальных отношений с Западом, чем граждане Европы, а тем более их правительства. Несмотря на все «межимпериалистические противоречия» и конкуренцию, в т.ч. транснациональных промыш-ленных конгломератов, они едины. Если говорить о ЕС, то его страны абсолютно самодостаточны в рамках союза 3 . Наш единственный аргумент, не считая ядерного оружия, в отношениях с Евросоюзом - это нефть и газ. Однако необходимо принимать во внимание, что для России поставки минерального сырья в ЕС по стоимости составляют $27,8 \%$ от объёма нашего экспорта, а доля нашего газа, нефти и угля в импорте ЕС $2,1 \% 4$. Если мы прекратим поставки энергетического сырья в Европу, $\mathrm{EC}^{5}$ и их союзники сделают всё, чтобы восполнить дефицит топлива, а нам придётся искать новые рынки для пополнения бюджета, больше, чем на 40\% зависящего от экспорта энергетического сырья.

Избежать негативных последствий для нашей страны от конфронтации с Западом, включая Украину, мы можем, только начав с ним конструктивные переговоры. Взаимные обвинения без признания тех решений, которые привели к кризису в наших отношениях, могут про-должаться до бесконечности. Мы должны начать поэтапно решать существующие

кают в 2022 г. Совсем не обязательно, что он воспользуется принятой поправкой и останется на новый срок. Однако если это произойдёт, то принцип несменяемости власти может привести Китай к непредсказуемым и опасным последствиям.

${ }^{1}$ Президент России. 01.03.2018. URL: kremlin.ru (дата обращения: 05.01.2019).

2 Президент России. 20.02.2019. URL: kremlin.ru (дата обращения: 07.03.2019).

3 Для большинства стран ЕС крупнейшими партнёрами по торговле являются их соседи по союзу. Только у Великобритании и Мальты в 2017 г. торговля внутри союза равна торговле со странами, не входящими в ЕС, у ос-тальных 26 государств торговля внутри ЕС в значительной степени ориентирована на внутренний товарооборот. В экспорте ЕС основными партнёрами за пределами союза являются США, Китай, Швейцария и Турция, в импорте - Китай, США, Россия. У 17 стран ЕС основные экспортные поставки приходится на Германию и лишь у самой ФРГ и Великобритании главными партнёрами по экспорту являются США. С учётом внутрисоюзной тор-говли ни у одной страны ЕС Китай, кроме ФРГ (КНР в 2018 г. была на втором месте, опережая Францию) не входит в первую тройку импортёров. В импорте для 18 стран ЕС основным партнёром является Германия, для Бельгии и ФРГ - это Нидерланды; остальные страны в основном предпочитают традиционных партнёров - Кипр, Грецию, Латвию, Литву, Португалию, Испанию и т.д. [Eurostat].

${ }^{4}$ COMTRADE. URL: https://comtrade.un.org/ (дата обращения: 07.03.2019).

5 В 2018 г. ЕС импортировал минеральное сырьё на сумму 611,2 млрд евро, из которых 279,6 млрд евро пришлось на три страны Евросоюза - это Великобритания и страны обладательницы крупных морских нефтяных и газовых терминалов - Бельгия и Нидерланды URL: https://comtrade.un.org/ (дата обращения: 07.03.2019). 
проблемы в наших отношениях с Киевом. Первым этапом переговорного процесса должно стать обсуж-дение больной для Донецка, Луганска, Киева и Москвы проблемы ЛНР и ДНР. Решение первой проблемы даст возможность найти приемлемое для всех решение остальных проблем рос-сийско-украинских отношений. Здесь важно то, что и Россия, и Украина, и Европа заинтересованы в решении сложившейся опасной ситуации, что предполагает достижение разумного компромисса. Следующим этапом должно стать восстановление наших отношений с Западом и создание благоприятных условий для поступательного развития России.

Приложения

Таблица 1

Динамика внешней торговли России (2013-2018), млрд евро

\begin{tabular}{|l|c|c|c|c|c|c|c|c|}
\hline & \multicolumn{2}{|c|}{2013} & \multicolumn{2}{c|}{2015} & \multicolumn{2}{c|}{2017} & \multicolumn{2}{c|}{2018} \\
\hline & импорт & экспорт & импорт & экспорт & импорт & экспорт & импорт & экспорт \\
\hline ЕС & $\mathbf{1 0 0 , 9 9}$ & $\mathbf{1 8 1 , 6}$ & $\mathbf{5 9 , 9}$ & $\mathbf{1 2 3 , 2}$ & $\mathbf{7 1 , 9}$ & $\mathbf{1 1 5 , 2}$ & $\mathbf{7 5 , 6}$ & $\mathbf{1 7 3 , 7}$ \\
\hline Нидерланды & 4,4 & 52,1 & 2,6 & 36,2 & 3,2 & 30,6 & 3,1 & 36,8 \\
\hline Германия & 28,5 & 17,3 & 17,1 & 14,3 & 20,1 & 13,7 & 21,6 & 28,9 \\
\hline Италия & 10,96 & 21,9 & 7,1 & 14,6 & 8,7 & 8,7 & 9,0 & 13,9 \\
\hline Франция & 9,8 & 4,5 & 5,0 & 2,8 & 8,1 & 2,9 & 8,1 & 6,6 \\
\hline ЕС- & 53,66 & 95,8 & 31,8 & 67,9 & 40,1 & 55,9 & 41,8 & 87,5 \\
\hline Прочие ЕС & 47,3 & 85,8 & 28,1 & 55,3 & 31,8 & 59,3 & 33,8 & 102,4 \\
\hline Китай & $\mathbf{4 0 , 0}$ & $\mathbf{2 6 , 8}$ & $\mathbf{3 1 , 7}$ & $\mathbf{2 5 , 5}$ & $\mathbf{4 2 , 8}$ & $\mathbf{3 2 , 2}$ & $\mathbf{4 4 , 2}$ & $\mathbf{4 7 , 4}$ \\
\hline МИР & $\mathbf{2 3 7 , 1}$ & $\mathbf{3 9 6 , 9 6}$ & $\mathbf{1 6 4 , 7}$ & $\mathbf{3 0 9 , 8}$ & $\mathbf{2 0 2 , 0}$ & $\mathbf{3 1 7 , 9}$ & $\mathbf{2 0 1 , 7}$ & $\mathbf{3 8 0 , 5}$ \\
\hline
\end{tabular}

Источник: UN COMTRADE (trademap.org).

*Торговля ЕС с учётом торгового оборота внутри союза.

Таблица 2

Импорт ЕС минерального топлива без учёта внутрисоюзной торговли, млрд евро

\begin{tabular}{|c|c|c|c|c|c|c|}
\hline & 2013 & 2014 & 2015 & 2016 & 2017 & 2018 \\
\hline Импорт ЕС энерг. сырья & $\mathbf{4 0 6 , 7}$ & $\mathbf{3 5 7 , 8}$ & $\mathbf{2 6 4 , 0}$ & $\mathbf{2 0 9 , 3}$ & $\mathbf{2 6 8 , 1}$ & $\mathbf{3 3 1 , 6}$ \\
\hline в т.ч. из России & 140,2 & 114,2 & 81,7 & 69,9 & 86,4 & 102,3 \\
\hline импорт ЕС нефти & 302,7 & 270,3 & 183,5 & 145,0 & 190,7 & 241,3 \\
\hline в т.ч. из России & 99,6 & 79,9 & 51,7 & 46,0 & 57,1 & 64,9 \\
\hline импорт ЕС газа & 73,9 & 60,9 & 56,4 & 44,8 & $\mathbf{5 0 , 6}$ & 63,0 \\
\hline в т.ч. из России & 36,0 & 29,8 & 26,1 & 20,6 & $\mathbf{2 3 , 7}$ & 29,7 \\
\hline импорт ЕС угля & 15,8 & 14,2, & 12,5 & 10,3 & 16,5 & 18,9 \\
\hline в т.ч. из России & 4,5 & 4,2 & 3,7 & 3,2 & 5,5 & 3,0 \\
\hline
\end{tabular}

Источник. Extra-EU_imports_total_and_from_Russia_2018.

Таблица 3

Мировые инвестиции в 2017 г., млрд долл.

\begin{tabular}{|l|c|c|c|c|}
\hline & \multirow{2}{*}{ Приток ПИИ в 2017 } & \multirow{2}{*}{ Отток ПИИ в 2017 } & \multicolumn{2}{|c|}{ Объём накопленных ПИИ на конец 2017 г. } \\
\cline { 4 - 5 } & & & Импорт & Экспорт \\
\hline Всего & 1430 & 1429,8 & 31524,4 & 30837,9 \\
\hline ЕСА & 275,4 & 342 & 7807,0 & 7799,0 \\
\hline Китай & 303,6 & 435,7 & 9123,98 & 10631,7 \\
\hline Япония & 136,3 & 124,6 & 1490,9 & 1482,0 \\
\hline Россия & 10,4 & 160 & 207,5 & 1519,98 \\
\hline
\end{tabular}

Источник: World Investment Report 2018 UNCTAD 2018 Geneva. P. 184-19.

Научно-аналитический вестник ИЕ РАН, 2019, №4 


\section{Список литературы}

Журкин В.В., Носов М.Г. Дональд Трамп и Европа. Современная Европа, №4, 2018. С. 1733.

Носов М.Г. Пейзаж после выборов. Современная Европа, №2, 2018. С. 5-17.

\section{References}

Energy balance sheets, 2018 edition. Luxembourg, EU, 2018.

EU Energy in Figures 2018, EU 2018.

EU External Action. URL: eeas.europe.eu (дата обращения: 12.01.2019).

Eurostat Statistics. Extra-EU imports total and from Russia 2018S.xlsx. URL: https://ec.europa. eu/eurostat/statistics-explained/index.php?title=File:Extra-EU_imports_total_and_from_Russia_20 18S.xlsx (дата обращения: 03.03.2019).

FRUS, Europe 1944.

Global R\&D funding Forecast 2019, R\&D Magazine Winter 2019.

IMF World Economic Outlook, April - 2018. URL: imf.org (дата обращения: 08.04.2019).

Nosov M.G. Pejzazh posle vyborov. Sovremennaya Evropa, №2, 2018. S. 5-17.

SIPRI Yearbook. 2018. P. 234. URL: https://www.sipri.org/yearbook/2018 (дата обращения: 08.03.2019).

World Investment Report 2018 UNCTAD, Geneva: 2018. P. 59. URL: https://unctad.org/en/ PublicationsLibrary/wir2018_en.pdf (дата обращения: 08.03.2019).

Zhurkin V.V., Nosov M.G. Donal’d Tramp i Evropa. Sovremennaya Evropa, №4, 2018. S. 1733.

\section{Russia and EU: Policy and Trade}

Author. Mikhail Nosov, Corresponding Member of the Russian Academy of Sciences, Member of the Executive Board of the Institute of Europe. Address: 11-3, Mokhovaya str., Moscow, Russia, 125009. E-mail: mikhailnosov@mail.ru.

Abstract: Today, Russia's relations with the EU have fallen to an extremely low level. They are determined by the current packages of political and economic sanctions imposed by the European Union against Russia in the period from March 2014 to the present time. They provide the ban on the entry into the EU for a number of high-ranking representatives of Russian officials and business elite, the expulsion of Russian diplomats and a number of measures limiting trade and economic relations. The negative political result of these sanctions was the growth of anti-Russian sentiment in Europe and partial isolation of Russia. The future of Russia strongly requires breaking the deadlock in relations with the West.

Key words: Russia, EU, USA, trade, investment.

DOI: http://dx.doi.org/10.15211/vestnikieran420196167 